\title{
Genetic Variations of VEGFA Gene Are Associated With Infiltration of Adjacent Tissues and the Clinical Outcome of Patients With Nasopharyngeal Carcinoma
}

\author{
ELIZABETH PSOMA ${ }^{1}$, GEORGIA-ANGELIKI KOLIOU ${ }^{2 *}$, FOTEINOS-IOANNIS DIMITRAKOPOULOS ${ }^{3 *}$, \\ KYRIAKI PAPADOPOULOU ${ }^{4}$, DIMITRA RONTOGIANNI ${ }^{5}$, MATTHEOS BOBOS ${ }^{4}$, \\ ANASTASIOS VISVIKIS ${ }^{6}$, PARIS A. KOSMIDIS ${ }^{7}$, GEORGE FOUNTZILAS ${ }^{4,8,9}$, \\ JANNIS CONSTANTINIDIS ${ }^{10}$ and ANNA KALOGERA-FOUNTZILA ${ }^{11}$ \\ ${ }^{1}$ Department of Radiology, AHEPA Hospital, Aristotle University of Thessaloniki, \\ School of Health Sciences, Faculty of Medicine, Thessaloniki, Greece; \\ ${ }^{2}$ Section of Biostatistics, Hellenic Cooperative Oncology Group, Data Office, Athens, Greece; \\ ${ }^{3}$ Division of Oncology, Department of Medicine, University Hospital, \\ Medical School, University of Patras, Patras, Greece; \\ ${ }^{4}$ Laboratory of Molecular Oncology, Hellenic Foundation for Cancer \\ Research/Aristotle University of Thessaloniki, Thessaloniki, Greece; \\ ${ }^{5}$ Department of Pathology, Evangelismos Hospital, Athens, Greece; \\ ${ }^{6}$ Third Department of Medical Oncology, Agii Anargiri Cancer Hospital, Athens, Greece; \\ ${ }^{7}$ Second Department of Medical Oncology, Hygeia Hospital, Athens, Greece; \\ ${ }^{8}$ Aristotle University of Thessaloniki, Thessaloniki, Greece; \\ ${ }^{9}$ German Oncology Center, Limassol, Cyprus; \\ ${ }^{10} 1^{\text {st }}$ Otolaryngology Department, Medical Department, School of Health Sciences, \\ Aristotle University of Thessaloniki, Thessaloniki, Greece; \\ ${ }^{11}$ Department of Radiology, AHEPA Hospital, Aristotle University of Thessaloniki, \\ School of Health Sciences, Faculty of Medicine, Thessaloniki, Greece
}

\begin{abstract}
Background/Aim: The aim of the present study was to investigate the clinical significance of 7 single nucleotide polymorphisms (SNPS) of vascular endothelial growth factor A (VEGFA), endothelin receptor type A (EDNRA), nibrin (NBS1) and Fas cell surface death receptor (FAS) genes in patients with nasopharyngeal carcinoma (NPC). Patients and Methods: Genomic DNA was extracted from the peripheral blood specimens of 60 patients. Genotyping of 4 VEGFA polymorphisms, namely VEGFA -1154 G/A (rs 1570360), -2578 $A / C$ (rs699947), $-1498 C / T(r s 833061)$ and $+936 C / T$
\end{abstract}

This article is freely accessible online.

*These Authors contributed equally to this study.

Correspondence to: Elizabeth Psoma, Department of Radiology, AHEPA Hospital, Kiriakidi 1, Thessaloniki 546 21, Thessaloniki, Greece. Tel: +30 2313303489, e-mail: elizabethpsoma@gmail.com

Key Words: Nasopharyngeal, cancer, CT, MRI, SNPs, polymorphism, variations, genotype, VEGFA, EDNRA NBS1, FAS. (rs3025039), as well as EDNRA SNP p.His323 (rs5333), NBS1 p.E185Q (rs1805794) and FAS -671 A/G (rs1800682) was performed by using Sanger sequencing. Results: The $V E G F A+936$ CC genotype was more frequent in tumors with bilateral infiltration of pterygoid plates compared to those with ipsilateral $(76.9 \%$ vs. $69.6 \%, p=0.008)$ and no infiltration of pterygoid plates (76.9\% vs. $68.8 \%, p=0.023)$. VEGFA -2578, VEGFA - 1154 and VEGFA +936 were significantly associated with infiltration to the pterygoid processes ( $p=0.011, p=0.041$ and $p=0.032$, respectively). EDNRA H323H TT genotype was marginally associated with infiltration to the ipsilateral medial pterygoid muscles $(p=0.045)$. A trend towards longer overall survival was observed for VEGFA -2578 CC as compared to AC (HR=0.24, $p=0.060)$. Conclusion: The studied VEGFA SNPs seem to be associated with the local extension of the NPC and maybe with the clinical outcome of this patient group.

Nasopharyngeal carcinoma (NPC) is a rare human malignancy with an annual incidence of 0.1-1.1/100,000 people with Caucasian origin in western countries. 
Particularly in Southeast Europe, the annual incidence reaches 1 per 100,000 inhabitants $(1,2)$. In contrast, the highest incidence rates are noted in Southern Asia, Alaska and the Mediterranean Basin (1). The unbalanced geographical incidence of this tumor may represent the role of the environment and the genetic background in the development of NPC $(3,4)$.

Imaging diagnosis of NPC is based on magnetic resonance imaging (MRI) along with computed tomography (CT), which accurately provide definition of the tumor extension and determine the treatment choice (5-9). The cornerstone of management of patients with early-stage NPC is radiation therapy (RT), while the combination of RT with chemotherapy is necessary for the management of locally advanced disease (10). Despite the combined imaging applications with RT and systemic therapies treatment still fails, especially when the tumor is in the advanced stage (11). Hence, prognostic factors, such as gene singlenucleotide polymorphisms (SNPs), needed to be further developed (12).

Many studies have shown that NPC pathogenesis is strongly associated with Epstein-Barr virus (EBV) infection, independently of ethnic origin, and for that reason NPC has been mainly characterized as a virus-related human malignancy $(13,14)$. In addition, it seems that EBV-related NPC is associated with a specific histological subtype. The undifferentiated type of NPC, strictly associated with EBV infection, is predominant in endemic areas, while the differentiated and non-keratinizing squamous cell variants are common in the USA and North European countries (11).

Except for EBV infection, multiple other factors participate in the pathogenesis of NPC, such as genetic, epigenetic and environmental factors as well as dietary habits (15). On the other hand, exposure to both radiation and chemicals can lead to lesions of genomic DNA. Double strand breaks (DSB) are a relatively dangerous form of DNA lesions, which, in combination with the failure of DNA repair mechanisms, can lead to genomic instability and probably cancer (6-8). Nibrin (NBS1) plays an important role in the cellular response to DNA damage and maintenance of genomic integrity. NBS1, as a part of a greater complex MRN (MRE11/RAD50/NBS1), modulates the DNA damage signal and promotes the repair (16). Any genetic variation of the NBS1 gene may have deleterious effects on cell capability to respond to DNA damage, predisposing to cancer and also to the genetic disease named Nijmegen Breakage Syndrome (NBS) (17).

Several studies have investigated a genetic variant of NBS1, E185Q polymorphism, in various types of cancer. A meta-analysis, a decade ago, showed that there might be an association between NBS1 $8360 \mathrm{G} / \mathrm{C}$ (E185Q) polymorphism and cancer risk, especially in Caucasians (18). Zeng et al., who carried out a hospital-based case-control study to investigate the possible relationship of the E185Q polymorphism with the risk of NPC in Chinese population, found a correlation with advanced NPC stage and with progression of the disease to invasive and metastatic (18, 19). Although the NBS1 E185Q polymorphism is a commonly studied polymorphism, this SNP has not been studied regarding its role in local extension of NPC.

In addition, angiogenesis also plays a significant role in NPC development and progression $(20,21)$. VEGFA is a central molecule in the angiogenesis process and for that reason numerous studies have investigated the clinical significance of VEGFA variants in cancer (22-24). In the current study, VEGFA - 1154 G/A (rs1570360), -2578 A/C (rs699947), -1498 C/T (rs833061) and +936 C/T (rs3025039) have been evaluated.

The axis of endothelin-1 (END1)/endothelin A receptor (EDNRA) also plays a significant role in angiogenesis. Focusing on the NPC, many publications have shown that EDNRA is overexpressed in $73.9 \%$ of NPC cases and it is also an independent prognostic factor for distant metastases (25). Furthermore, it has been shown that EDNRA SNP rs5333 has a prognostic significance for patients with locoregionally advanced NPC (26), as well as it has been associated with lower risk (grade 2-3) for radiation-induced xerostomia in NPC patients (27).

Another pivotal cellular function, a hallmark of cancer, is the apoptosis, which also exerts a central role in NPC (1). FAS is a cell surface receptor that can interact with its natural FAS ligand (FASL) to trigger apoptosis. Mutations in the FAS gene and its ligand can contribute to cell transformation by blocking the apoptotic signal transduction pathway, leading to loss of balance between proliferation and cell death (28). In addition, variations of FAS/FASL have been associated with impaired apoptosis in cancer. Particularly, in a meta-analysis of 52 studies, $\mathrm{Xu}$ et al. evaluated certain polymorphisms and found associations between different types of cancer. FAS $670 \mathrm{~A} / \mathrm{G}$ polymorphism was associated with decreased risk of prostate cancer and melanoma, while the FAS -1377 AA genotype had an increased risk for breast, gastric and esophageal cancer. In addition, the FASL -844 C/T polymorphism was correlated with increased risk for gastric, esophageal and ovarian cancer (29). Also, a specific SNP of $F A S,-670 \mathrm{~A} / \mathrm{G}$ (rs1800682), has attracted the interest as it has been associated with esophageal cancer, hepatocellular carcinoma, and prostate cancer susceptibility (30), as well as with papillary thyroid cancer (31). On the contrary, rs1800682 wasn't associated with cervical cancer risk (32).

In this study, we investigated the possible association between the aforementioned SNPs with clinicopathological parameters, disease extension to parapharyngeal spaces, infiltration to adjacent structures, metastasis to regional lymph nodes as well as with the clinical outcome of NPC patients. 


\section{Patients and Methods}

Patients. A cohort of 60 Greek patients with mainly locally advanced NPC, were retrieved from the Hellenic Cooperative Oncology Group (HeCOG) electronic database. Their formalin-fixed paraffin-embedded (FFPE) blocks and gDNA were also retrieved from the HeCOG's Tumor Repository and were analyzed in the Laboratory of Molecular Oncology (MOL, by the Hellenic Foundation for Cancer Research/Aristotle University of Thessaloniki, Thessaloniki, Greece). The study protocol was approved by the Bioethics Committee of the Aristotle University of Thessaloniki, School of Health Sciences, Faculty of Medicine (\#2/23March2016) and was designed according to the ethical guidelines of the Helsinki Declaration (2013) (33). Written informed consents were obtained from all participants.

The clinical, CT and MRI data of these patients, who were diagnosed with NPC, were retrospectively reviewed. We evaluated the involvement or infiltration of structures adjacent to the nasopharynx (especially the base of the skull) and of the parapharyngeal space. TNM staging was applied according to the revised 8th edition of the AJCC staging system (Table I). Tumor without extension to the parapharyngeal space (line from the free edge of the medial pterygoid plate to the lateral border of the carotid artery) was categorized as degree A (Figure 1). Tumor with extension to parapharyngeal space and infiltration of the medial/lateral pterygoid, and prevertebral muscles (line from the base of the medial pterygoid plate to the styloid process) was categorized as degree B (Figure 2). Tumor invasion of the bony structures of skull base and pterygoid structures (line from the edge of the lateral pterygoid process to the posterior border of the ascending branch of the mandible) was categorized as degree $\mathrm{C}$ (Figure 3). Tumor with intracranial extension and involvement of cranial nerves and hypopharynx was categorized as degree C (Figure 4). Patients were treated with induction chemotherapy followed by concurrent chemoradiotherapy or chemoradiotherapy alone.

SNPs selection. Literature (PubMed, Google Scholar) was reviewed by using suitable keywords (SNPs, nasopharyngeal cancer, risk, MRI, angiogenesis, apoptosis, biomarker, cancer). Particular SNPs were found in VEGFA, EDNRA, NBS1 and FAS genes, which had been previously assessed regarding their role in cancer. Their selection was based on the functionality as well as minor allele frequency. Based on these, VEGFA -1154 G/A (rs1570360), -2578 $\mathrm{A} / \mathrm{C}$ (rs699947), -1498 C/T (rs833061), located within the promoter and $+936 \mathrm{C} / \mathrm{T}$ (rs3025039) in the 3'-UTR region, as well as EDNRA SNP p.His323 (rs5333), a synonymous SNP in exon 6, NBS1 p.E185Q (rs1805794), a non-synonymous SNP within exon 5, and FAS $-670 \mathrm{~A} / \mathrm{G}$ (rs1800682), a SNP in the 5'-end regulatory, were finally selected. In all instances, the minus symbol (-) describes nucleotides before translation start site and plus $(+)$ nucleotides following translation end site.

SNPs genotyping. DNA was extracted from peripheral blood samples corresponding to the 60 patients under study, with a standard desalting method (34). Genotyping for the selected SNPs of VEGFA, EDNRA, FAS and NBS1 was performed with Sanger sequencing, as previously described (35).

The primers used for detection of VEGFA SNPs were (sense and antisense): -2578 A/G/C/T, 5'-AGGATGGGGCTGACTAGGTAA-3' and 5'-CCСCCTTTTCCTCCAACTCTC-3', 324 bp amplicon; -1498
Table I. TNM stage groups.

\begin{tabular}{lccc}
\hline Stage & $\mathrm{T}$ & $\mathrm{N}$ & $\mathrm{M}$ \\
\hline $\mathrm{I}$ & $\mathrm{T} 1$ & $\mathrm{~N} 0$ & $\mathrm{M} 0$ \\
$\mathrm{II}$ & $\mathrm{T} 1$ & $\mathrm{~N} 1$ & $\mathrm{M} 0$ \\
& $\mathrm{~T} 2$ & $\mathrm{~N} 0, \mathrm{~N} 1$ & $\mathrm{M} 0$ \\
$\mathrm{III}$ & $\mathrm{T} 1, \mathrm{~T} 2$ & $\mathrm{~N} 2$ & $\mathrm{M} 0$ \\
& $\mathrm{~T} 3$ & $\mathrm{~N} 0, \mathrm{~N} 1, \mathrm{~N} 2$ & $\mathrm{M} 0$ \\
IVA & $\mathrm{T} 4$ & $\mathrm{~N} 0, \mathrm{~N} 1, \mathrm{~N} 2$ & $\mathrm{M} 0$ \\
& Any T & Any N & $\mathrm{M} 0$ \\
IVB & Any T & & $\mathrm{M} 1$ \\
\hline
\end{tabular}

Stage IV compressed previous stage IVB now IVA.

C/T 5'-GCCCATTCCCTCTTTAGCCA-3' and 5'-AGTGAGG TTACGTGCGGACAG-3', 325 bp; -1154 G/A, 5'-CTGCTCCCT CCTCGCCAATGC -3' and 5'-CCAAGCCTCCGCGATCCT-3', 308 bp; +936 C/T, 5'-TCACCAGGAAAGACTGATACA-3' and 5'GGTGGGTGTGTCTACAGGA-3', 295 bp. Furthermore, the primers used for detection of EDNRA p.His323His were 5'- ATTCTTTC TCTGGTGTCTGC-3' and 5'-GAAAATCTGAGAAACTCCAAT-3', $281 \mathrm{bp}$; of $F A S-670 \mathrm{~A} / \mathrm{G}$ were 5'-TGCGATTTGGCTTAAGTTGT-3' and 5'-GGCTTCTGCTGTAGTTCAACC-3', 312 bp; of NBS1 p.E185Q 5'-AGAGAGATGAAAGGGAAA-3' and 5'- ATTACAT CCTGAAACAAGCAT-3', 333 bp amplicon, respectively.

Genotypic analysis of all SNPs involved polymerase chain reaction (PCR) amplification of the target gene region with the M13-coupled primers mentioned above, followed by Sanger sequencing. All PCR reactions were performed on a GeneAmp PCR system, while sense and antisense sequencing was carried out, using M13 forward and reverse primers, with the Big Dye Teminator kit v.1.1 (AppliedBiosystems, Foster City, CA, USA), according to the manufacturer's instructions. Samples were then purified utilizing the ethanol/EDTA precipitation protocol and loaded on the ABI 3130xl Genetic Analyzer. Sequences were visualized upon capillary electrophoresis in the ABI3130 genetic analyzer, initially called with the Sequencing Analysis software and further analyzed with the SeqScape software v2.5 (Applied Biosystems/Biosolutions, Athens).

Evaluation of EBV status. For the evaluation of EBV status, FFPE tumor tissue blocks were retrieved from the HeCOG Tumor Repository. EBV status was determined based on the assessment of EBV-encoded small RNA (EBER) using either the chromogenic in situ hybridization (CISH) or the polymerase chain reaction (PCR).

In the case of EBER detection by CISH, FFPE blocks underwent histological review by an experienced pathologist, who marked tumor dense areas for Tissue Microarray (TMA) construction. Upon histological evaluation, available tumors were transferred into lowdensity TMAs, whereby three cores $(0.6 \mathrm{~mm}$ in diameter) were obtained from appropriate regions of each tumor with the use of a manual arrayer (Model I, Beecher Instruments, San Prairie, WI) and included in the TMA block. Subsequently, EBER detection was performed on $4 \mu \mathrm{m}$ sections from the TMA block with the use of a Bond Max autostainer (Leica Microsystems, Wetzlar, Germany), according to the provider's specifications, as previously described (34-37). Tumor cells containing EBER transcripts were considered positive when an intense, brown, predominantly nuclear staining was present in $>1 \%$ of tumor cells (38). Only positive cases for the 


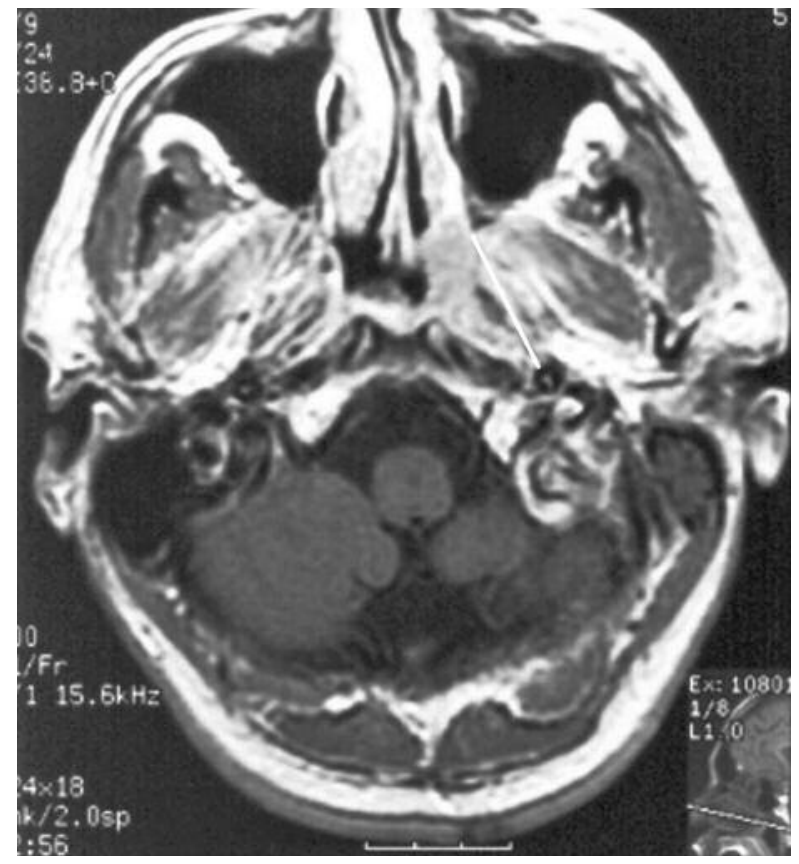

Figure 1. TIWI Gd. ST I. T1NOMO. Degree of parapharyngeal extension A.

poly-A probe, which is indicative of the preservation of intact mRNA in cells was considered eligible for assessment of EBER status. For PCR-based EBV detection, DNA was extracted from 10 $\mu \mathrm{m}$ FFPE sections, macrodissected manually to obtain tumor dense areas as marked on respective H\&E sections by the pathologist, using the QIAamp DNA Mini Kit (Qiagen GmbH, Hilden, Germany), according to standard procedures. For PCR-based EBV detection, specific primers were used targeting a segment of the BamH1W region, as described previously.

Statistical analysis. Group comparisons of categorical data were performed with the Chi-square or Fisher's exact (where appropriate) test. Overall survival (OS) was measured from the date of diagnosis to the date of patient's death or last contact, whichever occurred first. Survival curves were estimated using the Kaplan Meier method and compared across groups with the log-rank test. The associations between factors of interest and death rates were assessed with hazard ratios estimated with Cox proportional hazard regression models. Statistical significance was set at a two-sided $p<0.05$. Statistical analyses were performed using the Statistical Analyses Software (SAS; version 9.3, SAS Institute Inc., Cary, NC).

\section{Results}

Study population. Clinicopathological characteristics of the studied patients as well as tumor radiological parameters are shown in Table II. A total of 60 patients with NPC, aged between 14 and 78 years, were included in this study with $78.3 \%$ of the study population being males and $21.7 \%$ females. Histological subtype was confirmed from biopsies taken from the primary site or from infiltrated cervical lymph nodes in a

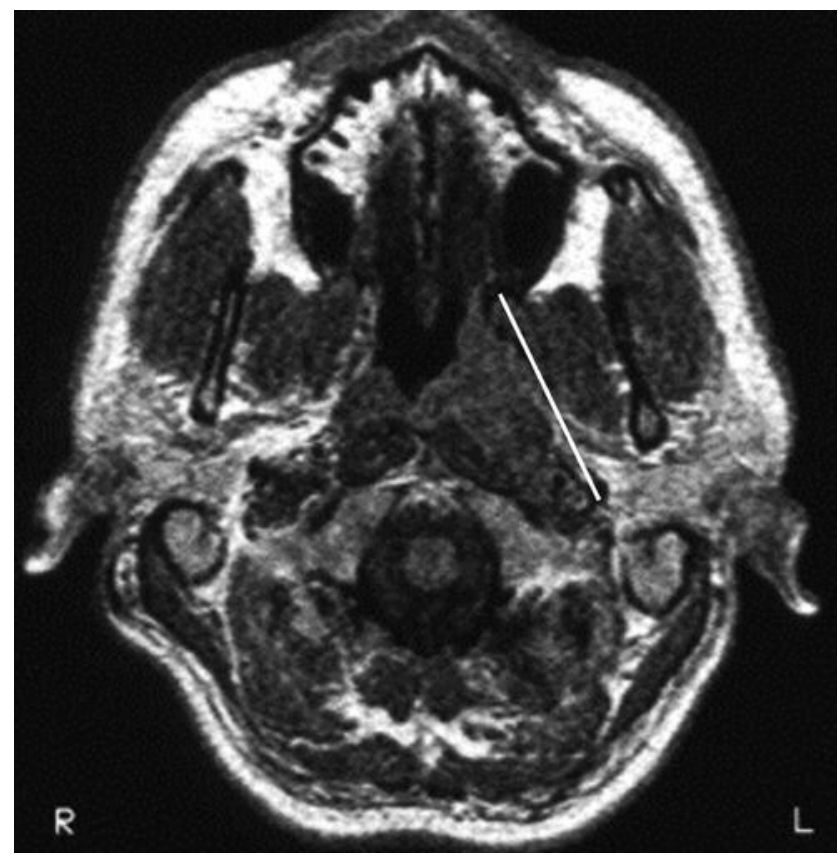

Figure 2. T1WI. ST II. T2N1MO. Degree of parapharyngeal extension A.

few cases. Thirty-five patients $(58.3 \%)$ had an undifferentiated carcinoma, 7 patients $(11.7 \%)$ had squamous cell carcinoma (SCC) and $18(30 \%)$ had a non-keratinising carcinoma. EBV status was available for 47 patients, with 43 of them were positive $(91.5 \%)$ and 4 were negative $(8.5 \%)$. The majority of patients $(81.7 \%)$ had stage II and III disease, while 10 patients had stage IV disease. Lateral extension A was observed in 20 patients $(33.3 \%)$, lateral extension $\mathrm{B}$ in $43.3 \%$ and $\mathrm{C}$ in $23.3 \%$ of the study cohort. It is of note that only 7 patients $(11.7 \%)$ had intracranial involvement, while $50 \%$ of the patients had one wall and the other $50 \%$ had two walls extension of the tumor. During the follow-up period [median 133.34 months (95\% CI=119.8-147.18)], one patient was lost from follow-up and 18 deaths (30\%) were reported. Thirteen of them $(72.2 \%)$ were due to NPC, 3 to other tumors, while one patient died of pneumonia and another due to old age. The median OS had not been reached yet at the time of the analysis. The 3- and 5-year OS rates were $86.2 \%$ and $80.8 \%$, respectively.

Genotype frequencies. The frequency distributions of the examined SNPs are presented in Table III. The genotyping results showed that most patients were heterozygous for VEGFA -2578 AC (50\%), VEGFA -1498 CT (45\%), VEGFA -1154 GG (41.1\%) and FAS -670 AG (66.1\%).

VEGFA +936 was associated with infiltration to the pterygoid plates. A significant association was observed between infiltration to the pterygoid plates and $V E G F A+936$ 

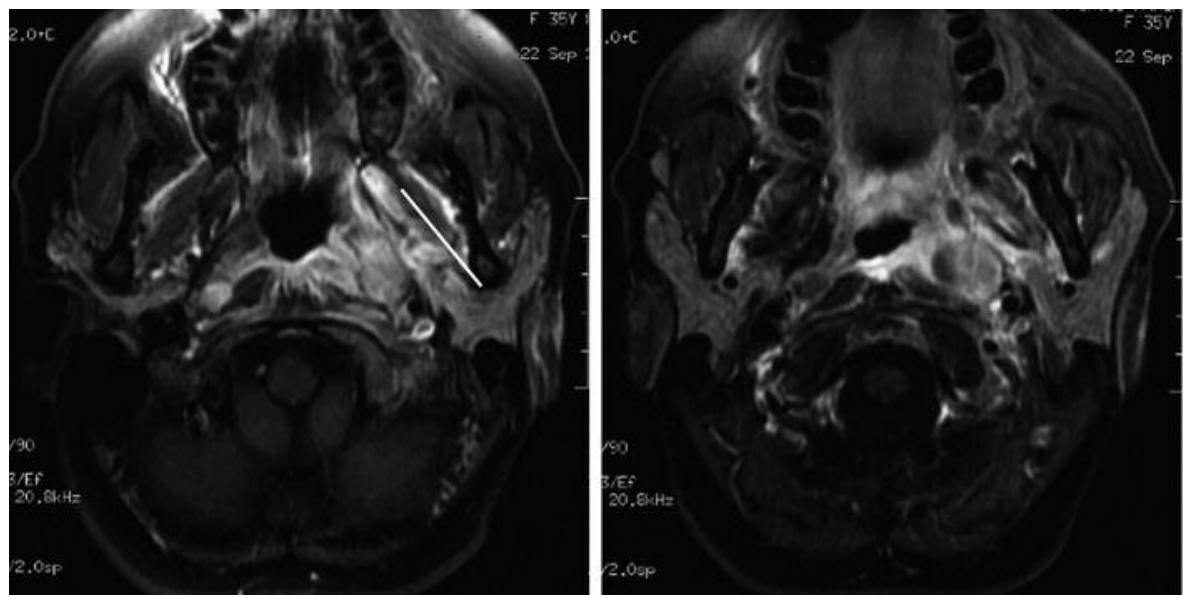

Figure 3. TIWI Gd. ST III. T3N2MO. Degree of parapharyngeal extension C.

$(p=0.008)$. Since there was only one patient with infiltration of contralateral pterygoid plates, the $2 \times 2$ associations between the rest of the categories were examined to detect where the true association lies. The VEGFA +936 CC genotype was found to be more frequent in tumors with bilateral infiltration of pterygoid plates as compared to those with ipsilateral $(76.9 \%$ vs. $69.6 \%, p=0.008)$ and no infiltration of pterygoid plates $(76.9 \%$ vs. $68.8 \%, p=0.023)$.

VEGFA -2578, VEGFA -1154 and VEGFA +936 were significantly associated with infiltration of the pterygoid processes. Additionally, VEGFA -2578, VEGFA -1154 and $V E G F A+936$ were significantly associated with infiltration to the pterygoid processes $(p=0.011, p=0.041$ and $p=0.032$, respectively). Examining the $2 \times 2$ associations among negative, ipsilateral and bilateral infiltration to pterygoid process, VEGFA -2578 AC was more frequent in tumors with ipsilateral infiltration to the pterygoid process as compared to those with negative infiltration $(71.4 \% v s .35 .3 \%, p=0.004)$ as well as compared to those with bilateral infiltration of pterygoid process $(71.4 \%$ vs. $40 \%, p=0.035)$. VEGFA -1154 GG was more frequent in tumors with infiltration of the bilateral pterygoid process as opposed to those with no infiltration $(73.3 \%$ vs. $21.1 \%, p=0.008)$ and $V E G F A+936 \mathrm{CC}$ was more frequently observed in tumors with bilateral than in tumors with ipsilateral infiltration of the pterygoid process (84.6\% vs. $66.7 \%, p=0.016)$. However, the power of these results is limited by the small number of patients in the groups under comparison and interpretation should be conducted with caution until further validation in larger cohorts.

SNPs and clinical outcome. In terms of OS, only a trend towards longer survival was observed for VEGFA -2578 CC as compared to $\mathrm{AC}(\mathrm{HR}=0.24,95 \% \mathrm{CI}=0.05-1.06, p=0.060)$,

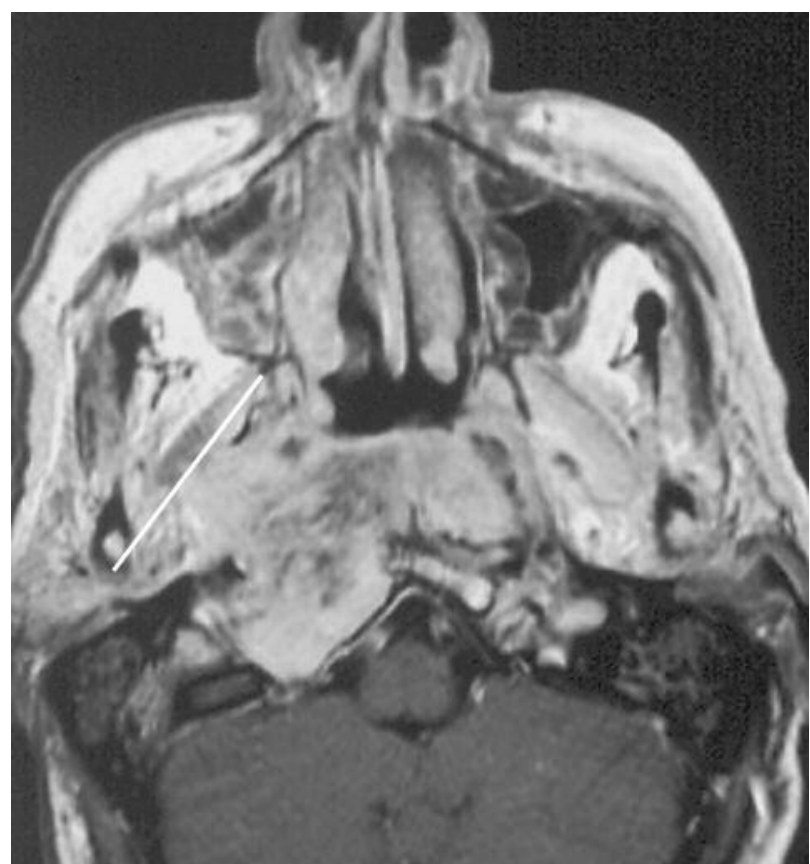

Figure 4. T1WI Gd. ST IV. T4N2MO. Degree of parapharyngeal extension $C$.

while the rest of the examined polymorphisms were not found to be prognostic for OS (Table IV). Upon adjustment for age, the only parameter that was found to marginally significantly affect OS in the univariate analysis, the hazard ratio for VEGFA -2578 CC was 0.28 (95\% CI=0.06-1.27), however statistical significance was not reached $(p=0.098)$. As previously, the power of the aforementioned results is reduced by the small number of patients experiencing the 
Table II. Patient and tumor characteristics.

\begin{tabular}{lc}
\hline & $\begin{array}{c}\text { Total } \\
(\mathrm{N}=60)\end{array}$ \\
\hline Age (median; range) & $50(14 ; 78)$ \\
\hline & $\mathrm{N}(\%)$ \\
\hline Gender & \\
Female & $13(21.7)$ \\
Male & $47(78.3)$ \\
Smoking & \\
No & $20(33.3)$ \\
Yes & $38(63.3)$ \\
Unknown & $2(3.3)$ \\
Alcohol use & \\
No & $49(81.7)$ \\
Yes & $8(13.3)$ \\
Unknown & $3(5.0)$ \\
EBV status & \\
Negative & $4(6.7)$ \\
Positive & $43(71.7)$ \\
Unknown & $13(21.7)$ \\
Histology classification & \\
Squamous cell carcinoma & $7(11.7)$ \\
Non-keratinising carcinoma & $18(30.0)$ \\
Undifferentiated & $35(58.3)$ \\
Stage & $1(1.7)$ \\
I & $23(38.3)$ \\
III & $26(43.3)$ \\
IVa & $8(13.3)$ \\
IVb & $2(3.3)$ \\
\hline &
\end{tabular}

event of interest in the comparable groups and need to be further validated in larger cohorts of NPC patients.

Associations with clinicopathological parameters. The associations of SNPs with selected clinical features are presented in Table V. Patients with undifferentiated tumors were more frequently homozygous GG for VEGFA -1154 $(p=0.030)$. In addition, smokers were less likely to have either VEGFA -1498 CT genotype (30.4\% vs. $60 \%$, $p=0.043)$ or -2578 AC $(44.1 \%$ vs. $61.1 \%, p=0.038)$ compared to non-smokers. No further significant associations were observed between the polymorphisms and the clinical characteristics.

No associations were observed with tumor extension. Similarly, no significant associations were observed between any of the examined polymorphisms and tumor location, lateral extension or infiltration to the prevertebral muscles (Table VI), while EDNRA H323H TT genotype was marginally significantly associated with infiltration to the ipsilateral medial pterygoid muscles $(p=0.045)$.

\begin{tabular}{lc}
\hline Radiological features & \\
\hline Intracranial involvement & $7(11.7)$ \\
& \\
Tumor location & $30(50.0)$ \\
One wall & $30(50.0)$ \\
Two walls & \\
Lateral extension & $20(33.3)$ \\
Lateral extension A & $26(43.3)$ \\
Lateral extension B & $14(23.3)$ \\
Lateral extension C & \\
Pterygoid processes & $20(33.3)$ \\
Negative & $24(40.0)$ \\
Ipsilateral & $1(1.7)$ \\
Contralateral & $15(25.0)$ \\
Bilateral & \\
Pterygoid plates & $18(30.0)$ \\
Negative & $26(43.3)$ \\
Ipsilateral & $1(1.7)$ \\
Contralateral & $15(25.0)$ \\
Bilateral & \\
Prevertebral muscles & $31(51.7)$ \\
Negative & $14(23.3)$ \\
Ipsilateral & $15(25.0)$ \\
Bilateral & \\
Medial pterygoid muscle & $14(23.3)$ \\
Negative & $24(40.0)$ \\
Ipsilateral & $22(36.7)$ \\
Bilateral & \\
Lymph node site & $5(8.3)$ \\
Negative & $1(1.7)$ \\
Ipsilateral & $29(48.3)$ \\
Contralateral & \\
Bilateral & \\
& \\
& \\
& \\
&
\end{tabular}

\section{Discussion}

The study of SNPs and their association with certain clinicopathological features, tumor development, progression and overall survival has become a hot area of cancer research $(39,40)$. Over the years, various technologies have been developed for efficient SNP genotyping, including arraybased hybridization, discrete PCR-based SNP assays as well as targeted Sanger sequencing, while recently the advent of next-generation sequencing technology (NGS) has allowed high-throughput but also flexible SNP genotypic analysis, proving advantage in terms of cost-effectiveness, number of SNPs and samples processed at once (41). This technological explosion has also helped the study of SNPs in the context of pharmacogenomics, contributing to the individualized management of cancer patients (42).

In the current study, seven SNPS of the VEGFA, EDNRA, NBS1 and FAS genes were evaluated in patients with NPC, assessing their correlations with clinicopathological parameters, radiologic traits and survival outcome of NPC patients. Three of these (VEGFA +936, VEGFA -2578, 
Table III. Frequency distribution of the examined SNPs.

\begin{tabular}{lc}
\hline & Total \\
& $(\mathrm{N}=60)$ \\
\hline$V E G F A-2578^{*}$ & \\
AA & $10(18.5)$ \\
AC & $27(50.0)$ \\
CC & $17(31.5)$ \\
$V E G F A-1498^{*}$ & \\
CC & $11(27.5)$ \\
CT & $18(45.0)$ \\
TT & $11(27.5)$ \\
$V E G F A-1154^{*}$ & \\
AA & $13(23.2)$ \\
GG & $23(41.1)$ \\
GA & $20(35.7)$ \\
$V E G F A+936^{*}$ & \\
CC & $37(69.8)$ \\
CT & $13(24.5)$ \\
TT & $3(5.7)$ \\
EDNRA H323H* & \\
CC & $3(5.4)$ \\
CT & $20(35.7)$ \\
TT & $33(58.9)$ \\
FAS -670* & \\
AA & $13(23.2)$ \\
AG & $37(66.1)$ \\
GG & $6(10.7)$ \\
NBS1 E185Q* & \\
GG & $9(15.8)$ \\
GC & $28(49.1)$ \\
\hline & $20(35.1)$ \\
\hline
\end{tabular}

*Data not available for all subjects, missing values: $V E G F A-2578=6$, VEGFA $-1498=20, V E G F A-1154=4, V E G F A+936=7, E D N R A$ $\mathrm{H} 323 \mathrm{H}=4$, FAS $-670=4$, NBS1 $\mathrm{E} 185 \mathrm{Q}=3$.

$V E G F A$-1154) seem to have a role in NPC. The fact that these SNPs are variants of the VEGFA gene, which is a significant component of angiogenesis, may reflects the important role of angiogenesis in NPC pathogenesis and development $(20,21)$. Our observation is supported from numerous studies, which have characterized these SNPs as functional and their status has been associated with risk, treatment response and prognosis of many malignant and non-malignant diseases (43-45). It seems that the studied SNPs exert a significant role in the pathogenesis of cancer affecting important functions, but their role needs to be clarified further in order to become clinically useful.

An interesting finding of the present study is the association of VEGFA +936 CC homozygosity with the infiltration to the pterygoid plates and processes. Although this SNP has been studied regarding its role in the NPC, this is the first report which associates VEGFA +936 with infiltration of NPC primary tumor adjacent tissues (46). Supportive to our observation is the fact the T allele of this SNP has been
Table IV. Hazard ratios and 95\% confidence intervals estimated with univariate Cox regression models with respect to OS.

\begin{tabular}{|c|c|c|c|}
\hline & Event/Total & HR $(95 \% \mathrm{CI})$ & $p$-Value \\
\hline \multicolumn{4}{|l|}{$V E G F A-2578$} \\
\hline $\mathrm{AA}$ & $2 / 10$ & $0.38(0.08-1.69)$ & 0.20 \\
\hline $\mathrm{AC}$ & $12 / 27$ & Reference & -- \\
\hline $\mathrm{CC}$ & $2 / 17$ & $0.24(0.05-1.06)$ & 0.060 \\
\hline \multicolumn{4}{|l|}{$V E G F A-1498$} \\
\hline $\mathrm{CC}$ & $4 / 11$ & $1.53(0.38-6.14)$ & 0.55 \\
\hline $\mathrm{CT}$ & $4 / 18$ & Reference & -- \\
\hline $\mathrm{TT}$ & $2 / 11$ & $0.73(0.13-3.99)$ & 0.72 \\
\hline \multicolumn{4}{|l|}{ VEGFA -1154 } \\
\hline AA & $3 / 13$ & $0.88(0.21-3.70)$ & 0.87 \\
\hline GG & $7 / 23$ & $1.35(0.43-4.27)$ & 0.61 \\
\hline GA & $5 / 20$ & Reference & -- \\
\hline \multicolumn{4}{|l|}{ NBS1 E185Q } \\
\hline $\mathrm{CC}$ & $3 / 9$ & $1.13(0.27-4.73)$ & 0.87 \\
\hline GG & $9 / 28$ & $1.41(0.47-4.27)$ & 0.54 \\
\hline GC & $5 / 20$ & Reference & -- \\
\hline \multicolumn{4}{|l|}{ Tumor location } \\
\hline One wall & $9 / 30$ & Reference & -- \\
\hline Two walls & $9 / 30$ & $1.05(0.41-2.64)$ & 0.93 \\
\hline \multicolumn{4}{|l|}{ Lateral extension } \\
\hline Lateral extension A & $4 / 20$ & Reference & -- \\
\hline Lateral extension $\mathrm{B}$ & $10 / 26$ & $2.67(0.83-8.65)$ & 0.10 \\
\hline Lateral extension $\mathrm{C}$ & $4 / 14$ & $2.18(0.54-8.83)$ & 0.27 \\
\hline \multicolumn{4}{|c|}{ Medial pterygoid muscle } \\
\hline Bilateral & $7 / 22$ & $1.01(0.32-3.21)$ & 0.98 \\
\hline Ipsilateral & $6 / 24$ & $0.70(0.21-2.31)$ & 0.56 \\
\hline Negative & $5 / 14$ & Reference & -- \\
\hline \multicolumn{4}{|l|}{ Prevertebral muscles } \\
\hline Bilateral & $2 / 15$ & $0.46(0.10-2.12)$ & 0.32 \\
\hline Ipsilateral & $7 / 14$ & $2.00(0.74-5.42)$ & 0.17 \\
\hline Negative & $9 / 31$ & Reference & -- \\
\hline Age & & $1.04(1.00-1.08)$ & 0.049 \\
\hline \multicolumn{4}{|l|}{ Smoking } \\
\hline No & $5 / 20$ & Reference & -- \\
\hline Yes & $13 / 38$ & $1.46(0.52-4.12)$ & 0.48 \\
\hline \multicolumn{4}{|l|}{ Stage } \\
\hline I-II & $7 / 24$ & $0.88(0.34-2.27)$ & 0.79 \\
\hline III-IV & $11 / 36$ & Reference & -- \\
\hline
\end{tabular}

HR: Hazard ratio; CI: confidence interval.

associated with plasma concentration (47) as well as with the expression in tumor tissues of VEGFA (48). Additionally, T allele of VEGFA +936 has been related to reduced risk for breast cancer in a cohort of Austrian individuals (49). Similarly to our findings, Liu et al. has documented that VEGFA +936 has no association with overall survival of patients with locoregionally advanced NPC treated with cisplatin- and fluorouracil-based chemoradiotherapy (50).

Our study further revealed an association of VEGFA -2578 AC genotype with increased frequency of ipsilateral infiltration of the pterygoid process. In addition, VEGFA -2578 CC genotype showed marginally favorable prognostic significance 
Table V. Associations of SNPs with selected clinicopathological parameters.

\begin{tabular}{|c|c|c|c|c|c|c|c|c|c|c|c|c|c|}
\hline & \multicolumn{3}{|c|}{ Gender } & \multicolumn{3}{|c|}{ Smoking } & \multicolumn{4}{|c|}{ Histology classification } & \multicolumn{3}{|c|}{ Stage } \\
\hline & Female & Male & $p$-Value & No & Yes & $p$-Value & Squamous & $\begin{array}{c}\text { Non- } \\
\text { keratinising }\end{array}$ & $\begin{array}{l}\text { Undifferen- } \\
\text { tiated }\end{array}$ & $p$-Value & $\begin{array}{l}\text { Stage } \\
\text { I-II }\end{array}$ & $\begin{array}{l}\text { Stage } \\
\text { III-IV }\end{array}$ & $p$-Value \\
\hline \multicolumn{14}{|c|}{$V E G F A-2578$} \\
\hline AA & $2(15.4)$ & $8(19.5)$ & 0.13 & $0(0.0)$ & $10(29.4)$ & 0.038 & $3(50.0)$ & $4(23.5)$ & $3(9.7)$ & 0.088 & $6(27.3)$ & $4(12.5)$ & 0.39 \\
\hline $\mathrm{AC}$ & $4(30.8)$ & $23(56.1)$ & & $11(61.1)$ & $15(44.1)$ & & $3(50.0)$ & $9(52.9)$ & $15(48.4)$ & & $10(45.5)$ & $17(53.1)$ & \\
\hline $\mathrm{CC}$ & $7(53.8)$ & $10(24.4)$ & & $7(38.9)$ & $9(26.5)$ & & $0(0.0)$ & $4(23.5)$ & $13(41.9)$ & & $6(27.3)$ & $11(34.4)$ & \\
\hline \multicolumn{14}{|c|}{ VEGFA -1498 } \\
\hline $\mathrm{CC}$ & $1(12.5)$ & $10(31.3)$ & 0.25 & $1(6.7)$ & $10(43.5)$ & 0.043 & $3(50.0)$ & $3(27.3)$ & $5(21.7)$ & 0.48 & $6(35.3)$ & $5(21.7)$ & 0.17 \\
\hline $\mathrm{CT}$ & $3(37.5)$ & $15(46.9)$ & & $9(60.0)$ & $7(30.4)$ & & $3(50.0)$ & $5(45.5)$ & $10(43.5)$ & & $9(52.9)$ & $9(39.1)$ & \\
\hline TT & $4(50.0)$ & 7 (21.9) & & $5(33.3)$ & $6(26.1)$ & & $0(0.0)$ & $3(27.3)$ & $8(34.8)$ & & $2(11.8)$ & $9(39.1)$ & \\
\hline \multicolumn{14}{|c|}{$V E G F A-1154$} \\
\hline AA & $1(7.7)$ & $12(27.9)$ & 0.29 & $2(10.5)$ & $10(28.6)$ & 0.28 & $4(57.1)$ & $4(23.5)$ & $5(15.6)$ & 0.030 & $7(30.4)$ & $6(18.2)$ & 0.53 \\
\hline GG & $7(53.8)$ & $16(37.2)$ & & $10(52.6)$ & $13(37.1)$ & & $0(0.0)$ & $5(29.4)$ & $18(56.3)$ & & $8(34.8)$ & $15(45.5)$ & \\
\hline GA & $5(38.5)$ & $15(34.9)$ & & $7(36.8)$ & $12(34.3)$ & & $3(42.9)$ & $8(47.1)$ & $9(28.1)$ & & $8(34.8)$ & $12(36.4)$ & \\
\hline \multicolumn{14}{|c|}{$V E G F A+936$} \\
\hline $\mathrm{CC}$ & $7(58.3)$ & $30(73.2)$ & 0.61 & $14(73.7)$ & $21(65.6)$ & 0.39 & $3(50.0)$ & $12(75.0)$ & $22(71.0)$ & 0.65 & $14(60.9)$ & $23(76.7)$ & 0.45 \\
\hline $\mathrm{CT}$ & $4(33.3)$ & $9(22.0)$ & & $5(26.3)$ & $8(25.0)$ & & $2(33.3)$ & $3(18.8)$ & $8(25.8)$ & & $7(30.4)$ & $6(20.0)$ & \\
\hline TT & $1(8.3)$ & $2(4.9)$ & & $0(0.0)$ & $3(9.4)$ & & $1(16.7)$ & $1(6.3)$ & $1(3.2)$ & & $2(8.7)$ & $1(3.3)$ & \\
\hline \multicolumn{14}{|c|}{ EDNRA $\mathrm{H} 323 \mathrm{H}$} \\
\hline $\mathrm{CC}$ & $2(15.4)$ & $1(2.3)$ & 0.19 & $2(10.0)$ & $1(2.9)$ & 0.45 & $0(0.0)$ & $1(5.6)$ & $2(6.5)$ & 0.92 & $1(4.8)$ & $2(5.7)$ & 0.73 \\
\hline $\mathrm{CT}$ & $4(30.8)$ & $16(37.2)$ & & $6(30.0)$ & $14(41.2)$ & & $2(28.6)$ & $6(33.3)$ & $12(38.7)$ & & $6(28.6)$ & $14(40.0)$ & \\
\hline TT & $7(53.8)$ & $26(60.5)$ & & $12(60.0)$ & $19(55.9)$ & & $5(71.4)$ & $11(61.1)$ & $17(54.8)$ & & $14(66.7)$ & $19(54.3)$ & \\
\hline \multicolumn{14}{|c|}{$F A S-670$} \\
\hline AA & $3(25.0)$ & $10(22.7)$ & 0.72 & $6(31.6)$ & $7(20.0)$ & 0.38 & $2(28.6)$ & $1(6.3)$ & $10(30.3)$ & 0.18 & $7(31.8)$ & $6(17.6)$ & 0.085 \\
\hline AG & $7(58.3)$ & $30(68.2)$ & & $10(52.6)$ & $25(71.4)$ & & $5(71.4)$ & $14(87.5)$ & $18(54.5)$ & & $15(68.2)$ & $22(64.7)$ & \\
\hline GG & $2(16.7)$ & $4(9.1)$ & & $3(15.8)$ & $3(8.6)$ & & & $1(6.3)$ & $5(15.2)$ & & $0(0.0)$ & $6(17.6)$ & \\
\hline \multicolumn{14}{|c|}{ NBS1 E185Q } \\
\hline $\mathrm{CC}$ & $4(30.8)$ & $5(11.4)$ & 0.24 & $4(20.0)$ & $5(14.3)$ & 0.52 & $1(16.7)$ & $2(11.1)$ & $6(18.2)$ & 0.27 & $3(13.0)$ & $6(17.6)$ & 0.65 \\
\hline GG & $5(38.5)$ & $23(52.3)$ & & $11(55.0)$ & $16(45.7)$ & & $5(83.3)$ & $10(55.6)$ & $13(39.4)$ & & $13(56.5)$ & $15(44.1)$ & \\
\hline GC & $4(30.8)$ & $16(36.4)$ & & $5(25.0)$ & $14(40.0)$ & & $0(0.0)$ & $6(33.3)$ & $14(42.4)$ & & $7(30.4)$ & $13(38.2)$ & \\
\hline
\end{tabular}

in univariate analysis, a relation which did not remain upon age adjustment. However, Wang et al. have demonstrated that NPC patients harboring the VEGFA -2578 CC genotype exhibited increased aggressiveness, larger size, poorer differentiation and advanced stage disease compared to patients harboring the VEGFA -2578 A allele (51). In addition, Nasr et al. have found a significant association between the VEGFA $-2578 \mathrm{C}$ allele carriers and aggressive forms of NPC, which were characterized by large tumors and advanced tumor stages (52).

Intriguing was also our finding that VEGFA -1154 GG was associated with infiltration to the bilateral pterygoid processes and to undifferentiated tumors. Interestingly, based on a metaanalysis from Hong et al., no association between VEGFA $1154 \mathrm{G} / \mathrm{A}$ polymorphism and the risk of cancer has been described with the exception of non-Caucasians, who seem to have higher cancer risk (53). In addition, Masago et al. have shown that VEGFA -1154 is an independent prognostic factor for NSCLC patients (54). Similarly, Verboom et al. have reported that rs 1570360 is associated with PFS in patients with advanced GIST receiving imatinib (55).
Various SNPs have also been identified on genes of EDN1 and EDNRA and have been associated with prognosis of some diseases. Colombo et al., reported that EDNRA $\mathrm{H} 323 \mathrm{H}$ polymorphism was associated with a substantially increased risk of heart failure while Herrmann et al. have found that the EDNRA/H323H polymorphism predicts survival in patients with dilated cardiomyopathy $(26,56-59)$. In our group, the EDNRA $\mathrm{H} 323 \mathrm{H}$ TT genotype was marginally significantly associated with infiltration to the ipsilateral medial pterygoid muscles. No statistically significant association was observed between the ENDRA polymorphism and tumor location or extension of the NPC.

Furthermore, it should be kept in mind that there are some limitations in the current study. First of all, a major limitation of our study is the small number of the enrolled patients, which didn't permit to show statistically significant associations. In addition, it would be more informative if a two-phase design had been followed and so, our results need further validation in a larger cohort. 
Table VI. Associations of SNPs with lateral extension, tumor location, prevertebral muscles and medial pterygoid muscles.

\begin{tabular}{|c|c|c|c|c|c|c|c|c|c|c|c|c|c|c|c|}
\hline \multirow[b]{3}{*}{$V E G F A-2578$} & \multicolumn{4}{|c|}{ Lateral extension } & \multicolumn{4}{|c|}{ Tumor location } & \multicolumn{3}{|c|}{ Prevertebral muscles } & \multicolumn{4}{|c|}{ Medial pterygoid muscles } \\
\hline & A & B & C $p$ & $p$-Value & $\begin{array}{l}\text { One } \\
\text { wall }\end{array}$ & $\begin{array}{l}\text { Two } P \\
\text { walls }\end{array}$ & $p$-Value & Negative & Ipsilateral & Bilateral $p$ & $p$-Value & Negative & Ipsilateral & Bilateral $l$ & $p$-Value \\
\hline & & & & 0.19 & & & 0.94 & & & & 0.54 & & & & 0.91 \\
\hline AA & $3(17.6)$ & $7(30.4)$ & $0(0.0)$ & & $4(16.7)$ & $6(20.0)$ & & $5(18.5)$ & $1(8.3)$ & $4(26.7)$ & & $3(27.3)$ & $4(19.0)$ & $3(13.6)$ & \\
\hline $\mathrm{AC}$ & $8(47.1)$ & $11(47.8)$ & $8(57.1)$ & & $2(50.0)$ & $15(50.0)$ & & $14(51.9)$ & $8(66.7)$ & $5(33.3)$ & & $5(45.5)$ & $10(47.6)$ & $12(54.5)$ & \\
\hline $\mathrm{CC}$ & $6(35.3)$ & $5(21.7)$ & $6(42.9)$ & & $8(33.3)$ & $9(30.0)$ & & $8(29.6)$ & $3(25.0)$ & $6(40.0)$ & & $3(27.3)$ & $7(33.3)$ & $7(31.8)$ & \\
\hline VEGFA -1498 & & & & 0.39 & & & 0.41 & & & & 0.69 & & & & 0.51 \\
\hline $\mathrm{CC}$ & $3(27.3)$ & $7(38.9)$ & $1(9.1)$ & & $5(25.0)$ & $6(30.0)$ & & $5(25.0)$ & $3(37.5)$ & $3(25.0)$ & & $3(27.3)$ & $5(31.3)$ & $3(23.1)$ & \\
\hline $\mathrm{CT}$ & $6(54.5)$ & $7(38.9)$ & $5(45.5)$ & & $11(55.0)$ & $7(35.0)$ & & $10(50.0)$ & $4(50.0)$ & $4(33.3)$ & & $7(63.6)$ & $6(37.5)$ & $5(38.5)$ & \\
\hline TT & $2(18.2)$ & $4(22.2)$ & $5(45.5)$ & & $4(20.0)$ & $7(35.0)$ & & $5(25.0)$ & $1(12.5)$ & $5(41.7)$ & & $1(9.1)$ & $5(31.3)$ & $5(38.5)$ & \\
\hline VEGFA -1154 & & & & 0.16 & & & 0.39 & & & & 0.92 & & & & 0.32 \\
\hline AA & $5(27.8)$ & $8(32.0)$ & $0(0.0)$ & & $6(22.2)$ & $7(24.1)$ & & $6(20.7)$ & $3(25.0)$ & 4 (26.7) & & $3(23.1)$ & $6(27.3)$ & $4(19.0)$ & \\
\hline GG & $7(38.9)$ & $8(32.0)$ & $8(61.5)$ & & $9(33.3)$ & $14(48.3)$ & & $11(37.9)$ & $5(41.7)$ & $7(46.7)$ & & $3(23.1)$ & $8(36.4)$ & $12(57.1)$ & \\
\hline GA & $6(33.3)$ & $9(36.0)$ & $5(38.5)$ & & $2(44.4)$ & $8(27.6)$ & & $12(41.4)$ & $4(33.3)$ & 4 (26.7) & & $7(53.8)$ & $8(36.4)$ & $5(23.8)$ & \\
\hline$V E G F A+936$ & & & & 0.38 & & & 0.21 & & & & 0.32 & & & & 0.27 \\
\hline $\mathrm{CC}$ & $11(64.7)$ & $16(69.6)$ & $10(76.9)$ & & $18(69.2)$ & $19(70.4)$ & & $22(78.6)$ & $8(66.7)$ & $7(53.8)$ & & $8(66.7)$ & $15(71.4)$ & $14(70.0)$ & \\
\hline $\mathrm{CT}$ & $6(35.3)$ & $4(17.4)$ & $3(23.1)$ & & $8(30.8)$ & $5(18.5)$ & & $5(17.9)$ & $4(33.3)$ & $4(30.8)$ & & $4(33.3)$ & $6(28.6)$ & $3(15.0)$ & \\
\hline TT & $0(0.0)$ & $3(13.0)$ & $0(0.0)$ & & $0(0.0)$ & $3(11.1)$ & & $1(3.6)$ & $0(0.0)$ & $2(15.4)$ & & $0(0.0)$ & $0(0.0)$ & $3(15.0)$ & \\
\hline EDNRA H323H & & & & 0.57 & & & 0.99 & & & & 0.41 & & & & 0.045 \\
\hline $\mathrm{CC}$ & $2(11.8)$ & $1(4.0)$ & $0(0.0)$ & & $1(3.8)$ & $2(6.7)$ & & $1(3.4)$ & $1(8.3)$ & $1(6.7)$ & & $0(0.0)$ & $1(4.8)$ & $2(9.1)$ & \\
\hline $\mathrm{CT}$ & $5(29.4)$ & $8(32.0)$ & $7(50.0)$ & & $9(34.6)$ & $11(36.7)$ & & $11(37.9)$ & $2(16.7)$ & 7 (46.7) & & $7(53.8)$ & $3(14.3)$ & $10(45.5)$ & \\
\hline TT & $10(58.8)$ & $16(64.0)$ & $7(50.0)$ & & $6(61.5)$ & $17(56.7)$ & & $17(58.6)$ & $9(75.0)$ & $7(46.7)$ & & $6(46.2)$ & $17(81.0)$ & $10(45.5)$ & \\
\hline$F A S-670$ & & & & 0.18 & & & 0.84 & & & & 0.60 & & & & 0.54 \\
\hline $\mathrm{AA}$ & $6(35.3)$ & $3(12.0)$ & $4(28.6)$ & & 7 (25.9) & $6(20.7)$ & & $5(18.5)$ & $5(35.7)$ & $3(20.0)$ & & $4(33.3)$ & $4(18.2)$ & $5(22.7)$ & \\
\hline AG & $10(58.8)$ & $20(80.0)$ & $7(50.0)$ & & $8(66.7)$ & $19(65.5)$ & & $20(74.1)$ & $7(50.0)$ & $10(66.7)$ & & 8 (66.7) & $16(72.7)$ & $13(59.1)$ & \\
\hline GG & $1(5.9)$ & $2(8.0)$ & $3(21.4)$ & & $2(7.4)$ & $4(13.8)$ & & $2(7.4)$ & $2(14.3)$ & $2(13.3)$ & & $0(0.0)$ & $2(9.1)$ & $4(18.2)$ & \\
\hline$N B S 1 \mathrm{E} 185 \mathrm{Q}$ & & & & 0.83 & & & 0.77 & & & & 0.39 & & & & 0.30 \\
\hline $\mathrm{CC}$ & $3(16.7)$ & $4(16.0)$ & $2(14.3)$ & & $4(14.8)$ & $5(16.7)$ & & $5(17.2)$ & $2(15.4)$ & $2(13.3)$ & & $0(0.0)$ & $6(27.3)$ & 3 (13.6) & \\
\hline GG & 7 (38.9) & $14(56.0)$ & $7(50.0)$ & & $2(44.4)$ & $16(53.3)$ & & $11(37.9)$ & $9(69.2)$ & $8(53.3)$ & & $7(53.8)$ & $9(40.9)$ & $12(54.5)$ & \\
\hline GC & $8(44.4)$ & $7(28.0)$ & $5(35.7)$ & & $11(40.7)$ & $9(30.0)$ & & $13(44.8)$ & $2(15.4)$ & $5(33.3)$ & & $6(46.2)$ & $7(31.8)$ & $7(31.8)$ & \\
\hline
\end{tabular}

In conclusion, three well described SNPs of the VEGFA gene (rs3025039, rs1570360, rs699947) seem to have an association with infiltration of adjacent tissues in patients with NPC, while rs699947 may also have prognostic value for the same patients. Further validation is needed in a larger cohort of NPC patients.

\section{Conflicts of Interest}

All Authors declare no financial competing interests regarding this study.

\section{Authors' Contributions}

Elizabeth Psoma: resources, investigation, writing-original draft preparation. Georgia-Angeliki Koliou: formal analysis, writingoriginal draft preparation. Foteinos-Ioannis Dimitrakopoulos: writing-original draft preparation. Kyriaki Papadopoulou: investigation, writing-review and editing. Dimitra Rontogianni: investigation. Mattheos Bobos: investigation. Anastasios Visvikis: resources. Paris A. Kosmidis: resources. George Fountzilas: resources. John Constantinidis: resources. Anna Kalogera-Fountzila: conceptualization, investigation, supervision.

\section{References}

1 Chou J, Lin YC, Kim J, You L, Xu Z, He B and Jablons DM: Nasopharyngeal carcinoma - review of the molecular mechanisms of tumorigenesis. Head Neck 30(7): 946-963, 2008. PMID: 18446839. DOI: 10.1002/hed.20833

2 Parkin DM and Muir CS: Cancer incidence in five continents. Comparability and quality of data. IARC Sci Publ 120: 45-173, 1992. PMID: 1284606.

3 Lo KW, To KF and Huang DP: Focus on nasopharyngeal carcinoma. Cancer Cell 5(5): 423-428, 2004. PMID: 15144950. DOI: $10.1016 / \mathrm{s} 1535-6108(04) 00119-9$

4 Post CM, Lin C, Adeberg S, Gupta M, Zhen W and Verma V: National practice patterns for clinical t1n0 nasopharyngeal cancer in the elderly: A national cancer data base analysis. Anticancer Res 38(3): 1651-1657, 2018. PMID: 29491098. DOI: 10.21873/anticanres.12397

5 Liao XB, Mao YP, Liu LZ, Tang LL, Sun Y, Wang Y, Lin AH, $\mathrm{Cui} \mathrm{CY}, \mathrm{Li} \mathrm{L}$ and Ma J: How does magnetic resonance imaging 
influence staging according to ajcc staging system for nasopharyngeal carcinoma compared with computed tomography? Int J Radiat Oncol Biol Phys 72(5): 1368-1377, 2008. PMID: 18455329. DOI: 10.1016/j.ijrobp.2008.03.017

6 Dubrulle F, Souillard R and Hermans R: Extension patterns of nasopharyngeal carcinoma. Eur Radiol 17(10): 2622-2630, 2007. PMID: 17404741. DOI: 10.1007/s00330-007-0616-Z

7 Zhang GY, Huang Y, Cai XY, Chen XP, Xu T, Wu J, Wei WH, Liu LZ, Huang ZL, Zhou MM, Xia ST and Wang YJ: Prognostic value of grading masticator space involvement in nasopharyngeal carcinoma according to $\mathrm{mr}$ imaging findings. Radiology 273(1): 136-143, 2014. PMID: 24844470. DOI: 10.1148/radiol.14132745

8 Xiao Y, Pan J, Chen Y, Lin S, Chen Y, Zong J, Fang Y, Guo Q, Chen B and Tang L: Prognostic value of mri-derived masticator space involvement in imrt-treated nasopharyngeal carcinoma patients. Radiat Oncol 10: 204, 2015. PMID: 26407897. DOI: 10.1186/s13014-015-0513-6

9 Kang M, Zhou P, Long J, Li G, Yan H, Feng G, Liu M, Zhu J and Wang R: A new staging system for nasopharyngeal carcinoma based on intensity-modulated radiation therapy (imrt). Oncotarget 8(55): 94188-94196, 2017. PMID: 29212220. DOI: 10.18632/oncotarget.21615

10 Lee AW, Ma BB, Ng WT and Chan AT: Management of nasopharyngeal carcinoma: Current practice and future perspective. J Clin Oncol 33(29): 3356-3364, 2015. PMID: 26351355. DOI: 10.1200/JCO.2015.60.9347

11 Rottey S, Madani I, Deron P and Van Belle S: Modern treatment for nasopharyngeal carcinoma: Current status and prospects. Curr Opin Oncol 23(3): 254-258, 2011. PMID: 21330921. DOI: $10.1097 / \mathrm{CCO} .0 \mathrm{~b} 013 \mathrm{e} 328344 \mathrm{f} 527$

12 Tan J, Jiang L, Cheng X, Wang C, Chen J, Huang X, Xie P, Xia D, Wang $R$ and Zhang Y: Association between VEGF-460t/c gene polymorphism and clinical outcomes of nasopharyngeal carcinoma treated with intensity-modulated radiation therapy. Onco Targets Ther 10: 909-918, 2017. PMID: 28243126. DOI: 10.2147/OTT.S126159

$13 \mathrm{Cao} \mathrm{Y}$ : Ebv based cancer prevention and therapy in nasopharyngeal carcinoma. NPJ Precis Oncol 1(1): 10, 2017. PMID: 29872698. DOI: 10.1038/s41698-017-0018-x

14 Klatka J, Hymos A, Szkatula-Lupina A, Grywalska E, Klatka B, Terpilowski $M$ and Stepulak A: T-lymphocyte activation is correlated with the presence of anti-ebv in patients with laryngeal squamous cell carcinoma. In Vivo 33(6): 2007-2012, 2019. PMID: 31662531 . DOI: 10.21873/invivo.11697

15 Kontos CK, Fendri A, Khabir A, Mokdad-Gargouri R and Scorilas A: Quantitative expression analysis and prognostic significance of the bcl2-associated $\mathrm{x}$ gene in nasopharyngeal carcinoma: A retrospective cohort study. BMC Cancer 13: 293, 2013. PMID: 23777485. DOI: 10.1186/1471-2407-13-293

16 Gollin SM: Mechanisms leading to chromosomal instability. Semin Cancer Biol 15(1): 33-42, 2005. PMID: 15613286. DOI: 10.1016/j.semcancer.2004.09.004

17 Chrzanowska KH, Gregorek H, Dembowska-Baginska B, Kalina MA and Digweed M: Nijmegen breakage syndrome (nbs). Orphanet J Rare Dis 7: 13, 2012. PMID: 22373003. DOI: 10.1186/1750-1172-7-13

$18 \mathrm{Lu} \mathrm{M}$, Lu J, Yang X, Yang M, Tan H, Yun B and Shi L: Association between the nbs 1 e185q polymorphism and cancer risk: A meta-analysis. BMC Cancer 9: 124, 2009. PMID: 19393077. DOI: 10.1186/1471-2407-9-124
19 Zheng J, Zhang C, Jiang L, You Y, Liu Y, Lu J and Zhou Y: Functional nbs1 polymorphism is associated with occurrence and advanced disease status of nasopharyngeal carcinoma. Mol Carcinog 50(9): 689-696, 2011. PMID: 21656575. DOI: $10.1002 / \mathrm{mc} .20803$

20 Kim TJ, Lee YS, Kang JH, Kim YS and Kang CS: Prognostic significance of expression of VEGF and cox-2 in nasopharyngeal carcinoma and its association with expression of c-erbb2 and egfr. J Surg Oncol 103(1): 46-52, 2011. PMID: 21031415. DOI: $10.1002 /$ jso. 21767

21 Saaristo A, Partanen TA, Arola J, Jussila L, Hytonen M, Makitie A, Vento S, Kaipainen A, Malmberg H and Alitalo K: Vascular endothelial growth factor-c and its receptor VEGFR-3 in the nasal mucosa and in nasopharyngeal tumors. Am J Pathol 157(1): 7-14, 2000. PMID: 10880369. DOI: 10.1016/S00029440(10)64510-5

22 Koutras AK, Antonacopoulou AG, Eleftheraki AG, Dimitrakopoulos FI, Koumarianou A, Varthalitis I, Fostira F, Sgouros J, Briasoulis E, Bournakis E, Bafaloukos D, Bompolaki I, Galani E, Kalogeras KT, Pectasides D, Fountzilas G and Kalofonos HP: Vascular endothelial growth factor polymorphisms and clinical outcome in colorectal cancer patients treated with irinotecan-based chemotherapy and bevacizumab. Pharmacogenomics J 12(6): 468-475, 2012. PMID: 21844885. DOI: $10.1038 /$ tpj.2011.37

23 Koutras A, Kotoula V and Fountzilas G: Prognostic and predictive role of vascular endothelial growth factor polymorphisms in breast cancer. Pharmacogenomics 16(1): 7994, 2015. PMID: 25560472. DOI: 10.2217/pgs.14.148

24 Norris CM, Shi W and Siemann DW: Impact of VEGF expression on the physiological characteristics of clonal cell lines. In Vivo 20(6B): 815-821, 2006. PMID: 17203773.

25 Mai HQ, Zeng ZY, Zhang HZ, Hou JH, Mo HY, Guo X, Min HQ and Hong MH: [correlation of endothelin a receptor expression to prognosis of nasopharyngeal carcinoma]. Ai Zheng 24(5): 611-615, 2005. PMID: 15890108.

26 Wen YF, Qi B, Liu H, Mo HY, Chen QY, Li J, Huang PY, Ye YF, Zhang Y, Deng MQ, Guo X, Hong MH, Cao KJ and Mai HQ: Polymorphisms in the endothelin-1 and endothelin a receptor genes and survival in patients with locoregionally advanced nasopharyngeal carcinoma. Clin Cancer Res 17(8): 2451-2458, 2011. PMID: 21487064. DOI: 10.1158/10780432.CCR-10-2264

27 Ma WL, Liu R, Huang LH, Zou C, Huang J, Wang J, Chen SJ, Meng XG, Yang JK, Li H, Yang GP and Guo CX: Impact of polymorphisms in angiogenesis-related genes on clinical outcomes of radiotherapy in patients with nasopharyngeal carcinoma. Clin Exp Pharmacol Physiol 44(5): 539-548, 2017. PMID: 28199751. DOI: 10.1111/1440-1681.12738

28 Villa-Morales M and Fernandez-Piqueras J: Targeting the fas/fasl signaling pathway in cancer therapy. Expert Opin Ther Targets 16(1): 85-101, 2012. PMID: 22239437. DOI: $10.1517 / 147282$ 22.2011 .628937

29 Xu Y, He B, Li R, Pan Y, Gao T, Deng Q, Sun H, Song G and Wang S: Association of the polymorphisms in the fas/fasl promoter regions with cancer susceptibility: A systematic review and meta-analysis of 52 studies. PLoS One 9(3): e90090, 2014. PMID: 24598538. DOI: 10.1371/journal.pone.0090090

30 Liu T, Zuo L, Li L, Yin L, Liang K, Yu H, Ren H, Zhou W, Jing $\mathrm{H}$, Liu $\mathrm{Y}$ and Kong C: Significant association among the fas - 
$670 \mathrm{a} / \mathrm{g}$ (rs1800682) polymorphism and esophageal cancer, hepatocellular carcinoma, and prostate cancer susceptibility: A meta-analysis. Tumour Biol 35(11): 10911-10918, 2014. PMID: 25085585. DOI: $10.1007 / \mathrm{s} 13277-014-2391-1$

31 Eun YG, Lee YC, Kim SK, Chung JH, Kwon KH and Park IS: Single nucleotide polymorphisms of the fas gene are associated with papillary thyroid cancer. Auris Nasus Larynx 42(4): 326-331, 2015. PMID: 258245544. DOI: 10.1016/ j.anl.2015.02.001

32 Zhang Y, Tong S, Guan L, Na F, Zhao W and Wei L: Cd95 rs 1800682 polymorphism and cervical cancer risk: Evidence from a meta-analysis. Tumour Biol 35(3): 1785-1790, 2014. PMID: 24114012. DOI: 10.1007/s13277-013-1237-6

33 World Medical A: World medical association declaration of helsinki: Ethical principles for medical research involving human subjects. JAMA 310(20): 2191-2194, 2013. PMID: 24141714. DOI: 10.1001/jama.2013.281053

34 Stavropoulou AV, Fostira F, Pertesi M, Tsitlaidou M, Voutsinas GE, Triantafyllidou O, Bamias A, Dimopoulos MA, Timotheadou E, Pectasides D, Christodoulou C, Klouvas G, Papadimitriou C, Makatsoris T, Pentheroudakis G, Aravantinos G, Karydakis V, Yannoukakos D, Fountzilas G and Konstantopoulou I: Prevalence of brca1 mutations in familial and sporadic greek ovarian cancer cases. PLoS One 8(3): e58182, 2013. PMID: 23536787. DOI: 10.1371/journal.pone.0058182

35 Koutras AK, Kotoula V, Papadimitriou C, Dionysopoulos D, Zagouri F, Kalofonos HP, Kourea HP, Skarlos DV, Samantas E, Papadopoulou K, Kosmidis P, Pectasides D and Fountzilas G: Vascular endothelial growth factor polymorphisms and clinical outcome in patients with metastatic breast cancer treated with weekly docetaxel. Pharmacogenomics J 14(3): 248-255, 2014 PMID: 24061601. DOI: 10.1038/tpj.2013.36

36 Krikelis D, Bobos M, Karayannopoulou G, Resiga L, Chrysafi S, Samantas E, Andreopoulos D, Vassiliou V, Ciuleanu E and Fountzilas G: Expression profiling of 21 biomolecules in locally advanced nasopharyngeal carcinomas of caucasian patients. BMC Clin Pathol 13: 1, 2013. PMID: 23360534. DOI: 10.1186/1472-6890-13-1

37 Weiss LM and Chen YY: Eber in situ hybridization for epsteinbarr virus. Methods Mol Biol 999: 223-230, 2013. PMID: 23666702. DOI: $10.1007 / 978-1-62703-357-2 \_16$

38 Boonkitticharoen V, Kulapaditharom B, Leopairut J, Kraiphibul P, Larbcharoensub N, Cheewaruangroj W, Chintrakarn C and Pochanukul L: Vascular endothelial growth factor a and proliferation marker in prediction of lymph node metastasis in oral and pharyngeal squamous cell carcinoma. Arch Otolaryngol Head Neck Surg 134(12): 1305-1311, 2008. PMID: 19075127. DOI: 10.1001/archotol.134.12.1305

39 Deng N, Zhou H, Fan H and Yuan Y: Single nucleotide polymorphisms and cancer susceptibility. Oncotarget $8(66)$ : 110635-110649, 2017. PMID: 29299175. DOI: 10.18632/ oncotarget.22372

40 Tan H: The association between gene snps and cancer predisposition: Correlation or causality? EBioMedicine 16: 8-9, 2017. PMID: 28163041. DOI: 10.1016/j.ebiom.2017.01.047

41 Wu MY, Huang SJ, Yang F, Qin XT, Liu D, Ding Y, Yang S and Wang XC: Detection of nasopharyngeal carcinoma susceptibility with single nucleotide polymorphism analysis using nextgeneration sequencing technology. Oncotarget 8(32): 5270852723, 2017. PMID: 28881764. DOI: 10.18632/oncotarget.17085
42 Palmirotta R, Carella C, Silvestris E, Cives M, Stucci SL, Tucci M, Lovero D and Silvestris F: Snps in predicting clinical efficacy and toxicity of chemotherapy: Walking through the quicksand. Oncotarget 9(38): 25355-25382, 2018. PMID: 29861877. DOI: $10.18632 /$ oncotarget.25256

43 Wang J, Shen C, Fu Y, Yu T and Song J: The associations between five polymorphisms of vascular endothelial growth factor and renal cell carcinoma risk: An updated meta-analysis. Onco Targets Ther 10: 1725-1734, 2017. PMID: 28356760. DOI: $10.2147 /$ OTT.S125965

$44 \mathrm{Xu} \mathrm{X}$, Du C, Li H, Du J, Yan X, Peng L, Li G and Chen ZJ: Association of VEGF genetic polymorphisms with recurrent spontaneous abortion risk: A systematic review and metaanalysis. PLoS One 10(4): e0123696, 2015. PMID: 25894555. DOI: 10.1371/journal.pone.0123696

45 Yadav BK, Yadav R, Chang H, Choi K, Kim JT, Park MS, Kang HG, Choo I, Ahn SH, Oh DS, Ha YS, Kim I, Seo MW and Shin BS: Genetic polymorphisms rs699947, rs1570360, and rs3025039 on the VEGF gene are correlated with extracranial internal carotid artery stenosis and ischemic stroke. Ann Clin Lab Sci 47(2): 144-155, 2017. PMID: 28442515.

46 Makni L, Stayoussef M, Ghazouani E, Mezlini A, Almawi WY and BesmaYacoubi L: Distinct association of VEGF-a polymorphisms with laryngeal and nasopharyngeal cancer. Meta Gene 10: 90-94, 2016. DOI: 10.1016/j.mgene.2016.02.003

47 Renner W, Kotschan S, Hoffmann C, Obermayer-Pietsch B and Pilger E: A common $936 \mathrm{c} / \mathrm{t}$ mutation in the gene for vascular endothelial growth factor is associated with vascular endothelial growth factor plasma levels. J Vasc Res 37(6): 443-448, 2000. PMID: 11146397 . DOI: 10.1159/000054076

48 Koukourakis MI, Papazoglou D, Giatromanolaki A, Bougioukas G, Maltezos E and Sivridis E: VEGF gene sequence variation defines VEGF gene expression status and angiogenic activity in non-small cell lung cancer. Lung Cancer 46(3): 293-298, 2004. PMID: 15541813. DOI: 10.1016/j.lungcan.2004.04.037

49 Krippl P, Langsenlehner U, Renner W, Yazdani-Biuki B, Wolf G, Wascher TC, Paulweber B, Haas J and Samonigg H: A common $936 \mathrm{c} / \mathrm{t}$ gene polymorphism of vascular endothelial growth factor is associated with decreased breast cancer risk. Int J Cancer 106(4): 468-471, 2003. PMID: 12845639. DOI: 10.1002/ijc.11238

50 Liu H, Qi B, Guo X, Tang LQ, Chen QY, Zhang L, Guo L, Luo DH, Huang PY, Mo HY, Xiang YQ, Qiu F, Sun R, Zhang Y, Chen MY, Hua YJ, Lv X, Wang L, Zhao C, Cao KJ, Qian CN, Hong $\mathrm{MH}$ and Mai HQ: Genetic variations in radiation and chemotherapy drug action pathways and survival in locoregionally advanced nasopharyngeal carcinoma treated with chemoradiotherapy. PLoS One 8(12): e82750, 2013. PMID: 24340057. DOI: 10.1371 /journal.pone.0082750

51 Wang T, Hu K, Ren J, Zhu Q, Wu G and Peng G: Polymorphism of VEGF-2578C/A associated with the risk and aggressiveness of nasopharyngeal carcinoma in a chinese population. Mol Biol Rep 37(1): 59-65, 2010. PMID: 19340604. DOI: 10.1007/ s11033-009-9526-2

52 Nasr HB, Chahed K, Bouaouina N and Chouchane L: Functional vascular endothelial growth factor $-2578 \mathrm{C} / \mathrm{A}$ polymorphism in relation to nasopharyngeal carcinoma risk and tumor progression. Clin Chim Acta 395(1-2): 124-129, 2008. PMID: 18588866. DOI: $10.1016 /$ j.cca.2008.05.022

53 Hong TT, Zhang RX, Wu XH and Hua D: Polymorphism of vascular endothelial growth factor $-1154 \mathrm{~g}>\mathrm{a}$ ( $\mathrm{rs} 1570360)$ with 
cancer risk: A meta-analysis of 16 case-control studies. Mol Biol Rep 39(5): 5283-5289, 2012. PMID: 22167330. DOI: 10.1007/s11033-011-1326-9

54 Masago K, Fujita S, Kim YH, Hatachi Y, Fukuhara A, Nagai H, Irisa K, Ichikawa M, Mio T and Mishima M: Effect of vascular endothelial growth factor polymorphisms on survival in advanced-stage non-small-cell lung cancer. Cancer Sci 100(10): 1917-1922, 2009. PMID: 19594543. DOI: 10.1111/j.13497006.2009.01253.x

55 Verboom MC, Kloth JSL, Swen JJ, van der Straaten T, Bovee J, Sleijfer S, Reyners AKL, Mathijssen RHJ, Guchelaar HJ, Steeghs $\mathrm{N}$ and Gelderblom H: Genetic polymorphisms in angiogenesisrelated genes are associated with worse progression-free survival of patients with advanced gastrointestinal stromal tumours treated with imatinib. Eur J Cancer 86: 226-232, 2017. PMID: 29054076. DOI: $10.1016 /$ j.ejca.2017.09.025

56 Herrmann S, Schmidt-Petersen K, Pfeifer J, Perrot A, BitAvragim N, Eichhorn C, Dietz R, Kreutz R, Paul M and Osterziel KJ: A polymorphism in the endothelin-a receptor gene predicts survival in patients with idiopathic dilated cardiomyopathy. Eur Heart J 22(20): 1948-1953, 2001. PMID: 11601839. DOI: 10.1053 /euhj.2001.2626
57 Colombo MG, Ciofini E, Paradossi U, Bevilacqua S and Biagini A: ET-1 lys198Asn and ET(A) receptor $\mathrm{H} 323 \mathrm{H}$ polymorphisms in heart failure. A case-control study. Cardiology 105(4): 246252, 2006. PMID: 16582543. DOI: 10.1159/000092374

58 Yasuda H, Kamide K, Takiuchi S, Matayoshi T, Hanada H, Kada A, Yang J, Miwa Y, Yoshii M, Horio T, Yoshihara F, Nakamura S, Nakahama H, Tei C, Miyata T and Kawano Y: Association of single nucleotide polymorphisms in endothelin family genes with the progression of atherosclerosis in patients with essential hypertension. J Hum Hypertens 21(11): 883-892, 2007. PMID: 17525706. DOI: $10.1038 /$ sj.jhh.1002234

59 Li H, Louey JW, Choy KW, Liu DT, Chan WM, Chan YM, Fung NS, Fan BJ, Baum L, Chan JC, Lam DS and Pang CP: EDN1 Lys198Asn is associated with diabetic retinopathy in type 2 diabetes. Mol Vis 14: 1698-1704, 2008. PMID: 18806884.

Received December 13, 2019

Revised December 23, 2019 Accepted January 6, 2020 